\title{
Bile acid studies in uncomplicated Crohn's disease
}

\author{
G. VANTRAPPEN, Y. GHOOS, P. RUTGEERTS, AND J. JANSSENS \\ From the Laboratory of Gastrointestinal Pathophysiology, Department of Medical Research, University of \\ Leuven, and the Department of Internal Medicine, University Hospital St. Rafaël, Leuven, B-3000, Belgium
}

SUMMARY The pool size and composition of bile acids were studied in 13 unoperated patients with uncomplicated Crohn's disease, 10 patients with ulcerative colitis, and 10 normal subjects. Many patients with Crohn's disease had in their bile a significantly increased amount of ursodeoxycholic acid. The bile acid pool size was significantly decreased and the ratio of glycine to taurine conjugates was significantly increased in the Crohn's disease patients. The reduction in bile acid pool size was related to the activity of the disease. The disorders of bile acid metabolism suggest that the intestinal involvement in Crohn's disease is much more extensive than can be demonstrated by careful radiological examinations.

In most patients with Crohn's disease inflammatory lesions involve the ileum, which is known to be the site of bile acid absorption. Therefore, effects on bile acid metabolism are to be expected in these patients. Previous investigations have shown changes in size and composition of the bile acid pool in several groups of patients in whom the ileum was resected or involved by some disease process (Austad et al., 1967; Hofmann, 1967; Meihoff and Kern, 1968; Bruusgaard and Thaysen, 1970; Dowling et al., 1972). Recently, the bile acid metabolism of patients with Crohn's disease was studied more specifically but the series comprised both operated and unoperated cases and it was not indicated whether or not the disease was complicated by fistula formation or obstruction (Lenz, 1975). The purpose of our investigations was to carry out a systematic study of bile acid composition and pool size in a group of unoperated patients with uncomplicated Crohn's disease in order to determine the disorders of bile acid metabolism which are apparently associated with the disease process itself.

\section{Methods}

\section{SUBJECTS}

Thirteen patients with Crohn's disease were studied, nine males and four females, aged 17 to 50 years with a mean age of 27.6 years. The diagnosis of Crohn's disease was based on generally accepted clinical, radiological, and pathological criteria. Patients who had been treated surgically for Crohn's

Received for publication 26 February 1977 disease or in whom the disease was complicated by intestinal fistulas or obstruction were excluded from the study. The radiologically demonstrable ileal lesions extended over a length of $5 \mathrm{~cm}$ to $50 \mathrm{~cm}$ (mean $28.5 \mathrm{~cm}$ ). In all but one of the patients the colon was involved as well. The activity of the disease was evaluated by means of the activity index proposed by the American National Cooperative Crohn's Disease Study Group (Best et al., 1976). This index is based on three clinical features (number of liquid stools, abdominal pain, general well-being) and on five objectively measurable items (systemic involvement, use of diphenoxylate or opiates, abdominal mass, haematocrit, and body weight). The numerical value of the index has been found to be proportional to the degree of illness: values of 150 and below are associated with quiescent disease, values above that indicate active disease, whereas values above 450 are seen with extremely severe disease. To correlate disease activity with parameters of bile acid metabolism a mean activity index was determined in each patient. This mean index was calculated from data recorded during the two or three clinical examinations that were performed in each patient during the two months preceding the bile acid studies. Some pertinent data on these patients are summarised in Table 1.

The control groups consisted of 10 normal subjects, six males and four females, aged 19 to 63 years (mean 35 years) and, of 10 patients with ulcerative colitis, six males and four females, aged 26 to 58 years (mean 34 years). The diagnosis of ulcerative colitis was confirmed histologically in all patients. 
Table 1 Clinical and laboratory data on series of patients with Crohn's disease

\begin{tabular}{|c|c|c|c|c|c|c|c|c|c|c|c|}
\hline Patient & $\begin{array}{l}\text { Age } \\
(y r)\end{array}$ & Sex & $\begin{array}{l}\text { Extent } \\
\text { of ileal } \\
\text { lesions } \\
(\mathrm{cm})\end{array}$ & $\begin{array}{l}\text { Other } \\
\text { localisations }\end{array}$ & $\begin{array}{l}\text { Activity } \\
\text { index }\end{array}$ & $\begin{array}{l}\text { Bile acid } \\
\text { pool }(g)\end{array}$ & $\begin{array}{l}\text { Sed. } \\
\text { rate } \\
(\mathrm{mm} / \mathrm{h})\end{array}$ & $\begin{array}{l}\text { Leucocyt. } \\
\left(\times 10^{\circ} / D\right)\end{array}$ & $\begin{array}{l}\text { Ser. } \\
\text { alb }(g / l)\end{array}$ & $\begin{array}{l}\text { Ser. } \\
\text { cholest. } \\
\text { ( } \mu \mathrm{mol} / \mathrm{l})\end{array}$ & $\begin{array}{l}\text { Ser. } \\
\text { carot. } \\
(\mu \mathrm{mol} / \mathrm{l})\end{array}$ \\
\hline VDV & 36 & $\mathbf{M}$ & 50 & Rectum, anus & 243 & $1 \cdot 4$ & 25 & $6 \cdot 2$ & $29 \cdot 8$ & $3 \cdot 8$ & 0.4 \\
\hline DA & 18 & $\mathbf{F}$ & 25 & Entire colon & 426 & 0.7 & 65 & $15 \cdot 4$ & $27 \cdot 1$ & $5 \cdot 0$ & 0.8 \\
\hline NJ & 22 & $\mathbf{M}$ & 15 & - & 46 & $1 \cdot 8$ & 13 & $6 \cdot 1$ & $39 \cdot 1$ & 3.4 & $1 \cdot 5$ \\
\hline GN & 26 & $\mathbf{F}$ & 15 & Colon segments, rectum & 526 & 0.6 & 68 & $6 \cdot 8$ & $25 \cdot 0$ & $6 \cdot 4$ & $1 \cdot 4$ \\
\hline $\mathbf{A L}$ & 26 & $\mathbf{M}$ & 20 & Caecum rectosigmoid & 276 & $1 \cdot 7$ & 26 & 8.4 & $22 \cdot 7$ & $3 \cdot 3$ & 0.9 \\
\hline VM & 22 & $\mathbf{M}$ & 30 & Right colon & 361 & $1 \cdot 6$ & 25 & $14 \cdot 6$ & $30 \cdot 5$ & $4 \cdot 2$ & $1 \cdot 7$ \\
\hline PA & 40 & $\mathbf{M}$ & 30 & Right colon & 144 & $2 \cdot 1$ & 10 & $10 \cdot 5$ & $35 \cdot 6$ & 3.5 & $1 \cdot 4$ \\
\hline JF & 35 & $\mathbf{M}$ & 10 & Colon segments, rectum & 348 & 0.9 & 17 & $10 \cdot 9$ & $42 \cdot 2$ & $4 \cdot 4$ & $1 \cdot 6$ \\
\hline BJ & 21 & $\mathbf{M}$ & 45 & Caecum & 140 & $1 \cdot 7$ & 24 & $12 \cdot 9$ & $29 \cdot 2$ & $3 \cdot 8$ & $1 \cdot 0$ \\
\hline VMJ & 20 & $\mathbf{F}$ & 25 & Colon segments & 69 & $2 \cdot 4$ & 27 & $8 \cdot 0$ & $41 \cdot 4$ & $4 \cdot 1$ & $1 \cdot 1$ \\
\hline MR & 22 & $\mathbf{F}$ & 50 & Caecum & 465 & 0.9 & 42 & 8.6 & 28.9 & $3 \cdot 8$ & $1 \cdot 1$ \\
\hline $\mathrm{CE}$ & 50 & $\mathbf{M}$ & 30 & Caecum, rectum & 217 & $2 \cdot 2$ & 22 & $4 \cdot 4$ & $24 \cdot 8$ & $3 \cdot 6$ & $1 \cdot 3$ \\
\hline
\end{tabular}

The degree of illness of these patients was at least as severe as that of the Crohn's patients. Application of the previously mentioned disease activity index to this group of patients indicated that the index was less than 150 in two, between 150 and 450 in six, and more than 450 in two patients.

\section{MATERIALS}

Ninety-nine per cent pure $\left({ }^{14} \mathrm{C}\right)$-cholic acid and ${ }^{14} \mathrm{C}$ )-chenodeoxycholic acid were purchased from Radiochemical Centre (Amersham, Eng.). The chemical purity was checked by thin-layer chromatography on silica gel G-plates (Merck, Germany) in the solvent system isooctane/ethylacetate/acetic acid (5:5:1) (Bruusgaard, 1970). The radiopurity was controlled by radioscanning (Berthold, model LB 2723; Erlangen, Germany) and was found to be greater than $99 \%$. All other radioactivity measurements were made with a liquid scintillation counter (Packard, model 2450; Downers Grove, Ill, USA). Quenching was corrected by external standardisation. The enzyme used for bile acids assays ( 3 alfahydroxysteroiddehydrogenase) was obtained from Worthington (Freehold, USA). Ursodeoxycholic acid, used as reference in the gas chromatographic analyses, was obtained from Steraloids (Pawling, NY, USA).

\section{ASSAYS}

Quantitative measurements of total bile acids and of individual bile acids after separation by thin-layer chromatography were performed enzymatically according to the method of Koss et al. (1965). For gas-liquid chromatographical analysis, the bile acids were subjected to alkaline hydrolysis, methylated with diazomethane and separated as methylesteracetates on $3 \%$ OV-1 or $3 \%$ OV-17 columns in a Pye Unicam gas chromatograph, model 104. Nordeoxycholic acid was used as internal standard. Bile acids were gained from fresh bile by liquid-solid extraction on Amberlite XAD-2 (Servachrome XAD-2, 100-200 $\mathrm{nm}$, Serva Heidelberg, Germany) according to the method of Schwarz et al. (1974). Taurine conjugates, glycine conjugates, and total unconjugated bile acids were separated by thin-layer chromatography on silica gel G-plates (Merck, Darmstadt, Germany) in the solvent propionic acid/isoamylacetate/propanol/ water (15:20:10:5) (Hofmann, 1962). Individual bile acids were determined by thin-layer chromatography in the solvent system isooctane/ethylacetate/acetic acid $(5: 5: 1)$.

The duodenal and ileal contents of four patients with Crohn's disease were submitted to the procedures described by Parmentier and Eyssen (1975) and Eyssen et al. (1976) in order to determine whether or not sulphated bile acids were present and, if so, to determine their concentration.

Results were statistically analysed using Student's $t$ test and standard correlation techniques. Data are expressed as mean values \pm SEM.

\section{POOL SIZE MEASUREMENT}

The pool size was measured according to the method of Austad et al. (1967). After an overnight fast a radio-opaque catheter was positioned in the duodenum under fluoroscopic control and $5 \mu \mathrm{Ci}\left({ }^{14} \mathrm{C}\right)$-cholic acid was administered intravenously. Three hours later gallbladder evacuation was stimulated with $1 \mathrm{U} / \mathrm{kg}$ body weight of pancreozymin (Boots Comp., Nottingham, Eng.), the duodenal contents were collected for $\mathbf{4 0}$ minutes, and the total volume was measured. Ten millilitres of bile were taken for analysis and the remainder was reinstilled into the duodenum.

\section{SPECIAL INVESTIGATIONS}

In the course of the study we found that patients with Crohn's disease have a significantly increased amount of ursodeoxycholic acid in their bile. To investigate 
this observation $5 \mu \mathrm{Ci}\left({ }^{14} \mathrm{C}\right)$-chenodeoxycholic was administered intravenously to three Crohn's disease patients with a high level of ursodeoxycholic acid. Twenty-four hours later gallbladder evacuation was stimulated, the duodenal contents were aspirated, and the nature of the labelled bile acids was determined. The sensitivity of the detection procedure was $2 \%$ of the administered dose.

\section{Results}

BILE ACID POOL SIZE

The bile acid pool size of the 13 patients with Crohn's disease was $1 \cdot 48( \pm 0 \cdot 16) \mathrm{g}$. A significantly larger pool was found in the normal subjects $(3.09 \pm 0.27) \mathrm{g}$ and in the patients with ulcerative colitis $(2.92 \pm 0.40) \mathrm{g}$ $(P<0.001$ and $P<0.01$ respectively). There was little overlap between the values of Crohn's disease patients and normal controls, but the overlap with ulcerative colitis, was considerable (Fig. 1).

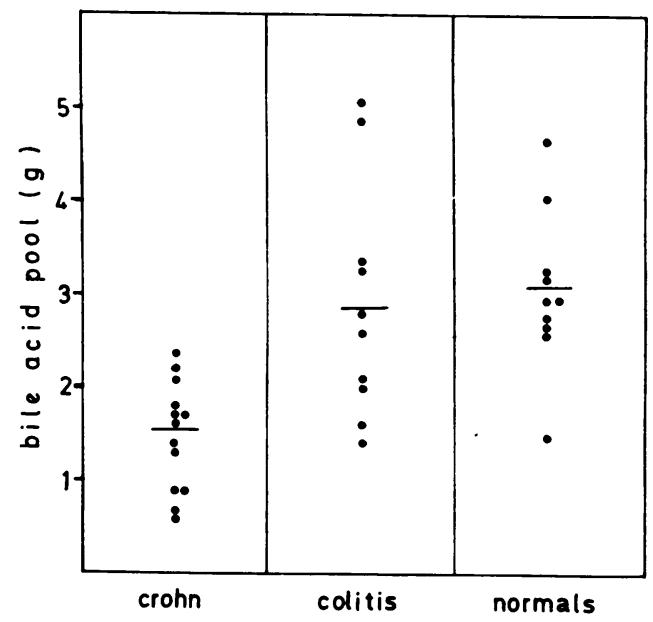

Fig. 1 Bile acid pool size in patients with Crohn's disease, patients with ulcerative colitis, and normal subjects.

COMPOSITION OF BILE ACID POOL

The ratio of glycine to taurine conjugates, the percentages of unconjugated bile acids and the relative amounts of the various cholanic acids in the bile acid pool of Crohn's disease patients, patients with ulcerative colitis, and normal controls are summarised in Table 2. In two patients with ulcerative colitis an unidentified bile acid was found which constituted $38.2 \%$ and $24.6 \%$ respectively of the bile acid pool. The most striking feature, however, was the increased amount of ursodeoxycholic acid in the bile of many patients with Crohn's disease
$(6.60 \% \pm 1.93 \%)$ as compared with $1.39 \%$ $( \pm 0.12 \%)$ in normal subjects and $0.72 \%( \pm 0.34 \%)$ in patients with ulcerative colitis $(\mathrm{P}<0.02)$ (Fig. 2). Unconjugated bile acids constituted $4.64 \%$ $( \pm 1.64 \%)$ of the pool in Crohn's disease patients, $2.59 \%( \pm 1.17 \%)$ in the normal subjects and $7.02 \%$ $( \pm 2.70 \%)$ in patients with ulcerative colitis. Only traces of sulphated bile acids were found in the Crohn's disease patients (less than $0.5 \%$ of the pool). The ratio of glycine to taurine conjugates was markedly greater in Crohn's disease patients than in normal subjects $(5.15 \pm 0.39$ and $2.35 \pm 0.17$ respectively; $P<0.001)$. Patients with ulcerative colitis had a glycine to taurine ratio which was not different from the normal controls $(2 \cdot 22 \pm 0.27)$ (Table 3).

\section{Discussion}

Previous investigations have shown bile acid loss in a variety of pathological conditions of the ileum including ileal resection and Crohn's disease (Austad et al., 1967; Hofmann, 1967; Meihoff and Kern, 1968; Bruusgaard and Thaysen, 1970; Dowling et al., 1972; Lenz, 1975). However, until now no systematic study has been performed of the bile acid composition and pool size in uncomplicated Crohn's disease - that is, without intestinal fistulas, radiologically demonstrable obstruction or ileal resection, conditions which are known to produce disorders of bile acid metabolism. Our studies were carried out in order to determine the disorders that are associated with the disease process itself.

We used the single duodenal intubation technique of Austad et al. (1967) to determine the bile acid pool size. In this method $\left({ }^{14} \mathrm{C}\right)$-cholic acid is administered intravenously; three hours later gallbladder evacuation is stimulated by cholecystokinin and bile is aspirated from the duodenum. If the injected label is homogeneously mixed with the gallbladder bile within three hours, the bile acid pool size can be calculated from the concentration of total bile acids and the dilution of the label in the bile sample. This procedure has been validated by Pomare and Low-Beer (1974) and by Duane et al. (1975). The latter authors used a longer time interval between administration of the label and duodenal sampling in order to allow more time for the label to mix with the gallbladder bile. The single intubation method will overestimate the pool size in conditions in which the fractional turnover rate is accelerated, such as in bile acid malabsorption (Duane et al., 1975). Our data indicate that, even if a method is used which possibly overestimates the pool size in patients with Crohn's disease involving the ileum, the bile acid pool of these patients is significantly reduced. As in patients 
Table 2 Size and composition of bile acid pool in patients with Crohn's disease, patients with ulcerative colitis, and normal subjects

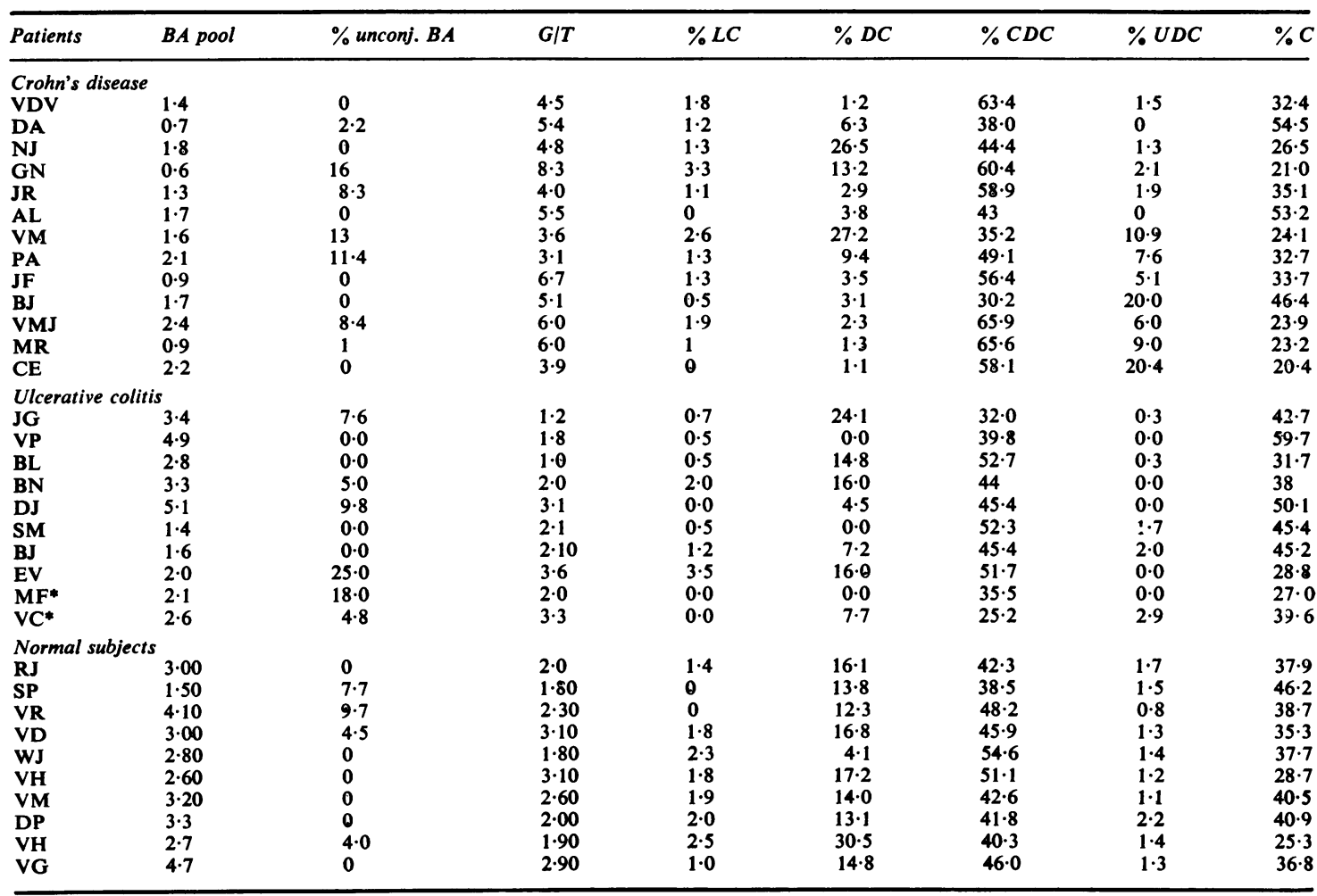

BA : bile acids, G/T: ratio of glyco/tauro conjugates, LC: lithocholic acid, DC: deoxycholic acid, CDC: chenodeoxycholic acid, UDC: ursodeoxycholic acid, $\mathrm{C}$ : cholic acid. Bile acids are expressed as per cent of total bile acid amount.

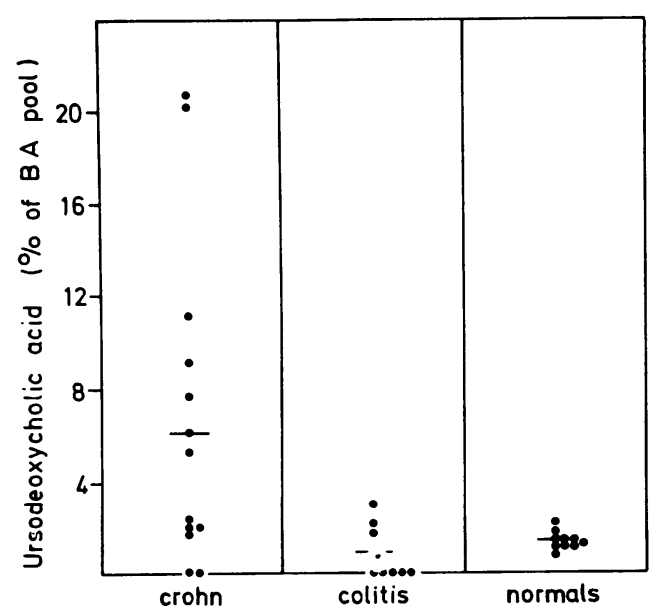

Fig. 2 Ursodeoxycholic acid in patients with Crohn's disease, patients with ulcerative colitis, and normal subjects.
Table 3 Correlation of Crohn's disease activity index with various parameters

\begin{tabular}{lll}
\hline Parameter & Correlation coefficient & Statistical significance \\
\hline Extent of disease & 0 & NS \\
Serum $\beta$-carotene & 0.29 & NS \\
Leucocyte count & 0.21 & NS \\
Serum albumin & 0.48 & NS \\
Serum cholesterol & 0.62 & P $<0.05$ \\
ESR & 0.66 & P $<0.01$ \\
BA pool size & 0.79 & P $<0.001$
\end{tabular}

ESR : erythrocyte sedimentation rate; BA: bile acid; NS: not signifcant.

with Crohn's disease or other disorders of the terminal ileum the bile acid pool size tends to become smaller as the day progresses (van Deest et al., 1968), it should be emphasised that we measured the size of the fasting pool. Gallstones are common in Crohn's patients (Heaton and Read, 1969; Dowling et al., 1972), and gallstone disease is often associated with a reduced bile acid pool (Vlahcevic et al., 1972). The 
decreased bile acid pool observed in this series of patients with Crohn's disease is not due to associated gallstone disease because none of the patients had gallstones on $x$-ray examination. It seems logical, therefore, to assume that the decreased bile acid pool size is related to an exaggerated loss of bile acids by the diseased ileum. As we did not culture the bacterial contents of the upper small intestine, we do not know whether the increased glycine to taurine ratio is caused by an interrupted enterohepatic circulation of bile acids (Garbutt et al., 1969), or to bacterial overgrowth (Tabaqchali, 1970; Mallory et al., 1973), or to both. The presence of unconjugated bile acids in the patients with Crohn's disease also points to the possibility of bacterial colonisation of the small intestine.

Impaired absorption of bile acids in the ileum can be compensated within certain limits by an increased bile acid synthesis (Hofmann and Poley, 1972). In Rhesus monkeys bile acid pool size is lowered only by ileal resections of more than one-third of the small bowel (Dowling et al., 1970). In man diarrhoea is observed with small ileal resections of 40 to $200 \mathrm{~cm}$ (Hofmann and Poley, 1972) but a decrease of bile acid pool size (as evidenced by decreased jejunal bile acid concentrations after a test meal) is observed only with resections of more than $100 \mathrm{~cm}$ (Hofmann and Poley, 1969). In our series of patients with Crohn's disease the radiologically demonstrable lesions were limited to the distal 5 to $50 \mathrm{~cm}$ of the small bowel. The reduction of their bile acid pool size to half the value of that found in normal subjects, therefore, strongly suggests that the intestinal segment in which bile acid absorption was impaired was much more extensive than the lesions demonstrated by careful radiological examinations. These data are in accordance with the observation of others who showed that Crohn's disease is a much more widespread intestinal disease than is generally believed (Goodman et al., 1976; Dyer et al., 1970; Ruddell et al., 1976).

An unexpected finding in the patients with Crohn's disease was the increased level of an unusual bile acid-that is, ursodeoxycholic acid, which is the epimer of chenodeoxycholic acid. Ursodeoxycholic acid, a major constituent of bile in bears, is only rarely found in measurable amounts in human subjects beyond the period immediately after birth (Murphy and Signer, 1974). Studies of Makino et al. (1975) have shown that orally administered ursodeoxycholic acid can be used in man todissolvecholesterol gallstones. Ursodeoxycholic acid was found in considerable amounts in the bile of patients who had been treated for long periods with chenodeoxycholic acid for the dissolution of gallstones (Salen et al., 1974; Stiehl et al., 1975; Bremmelgaard and Pedersen,
1976). The studies of Salen et al. (1976) indicate that ursodeoxycholic acid, administered as $\left({ }^{14} \mathrm{C}\right)$ ursodeoxycholic acid to five male subjects, may be transformed into chenodeoxycholic acid. The reverse reaction, however-that is, from cheno into ursohas not been demonstrated in man. Our observation that significant amounts of radioactive ursodeoxycholic acid could not be detected in the bile 24 hours after the intravenous administration of $\left({ }^{14} \mathrm{C}\right)$ labelled chenodeoxycholic acid is not in favour of the assumption that the increased levels of ursodeoxycholic acid in our Crohn's patients are due to transformation of cheno- into ursodeoxycholic acid. The origin of this bile acid remains unexplained.

Increased levels of ursodeoxycholic acid were found in Crohn's disease and not in ulcerative colitis. However, other pathological conditions such as exaggerated bile acid formation caused by ileal resection, bacterial overgrowth, and involvement of the ileum by other pathological conditions have to be studied before a high level of ursodeoxycholic acid can be accepted as a hallmark of Crohn's disease.

The activity of Crohn's disease was evaluated by the activity index proposed by the American National Cooperative Crohn's Disease Study

\section{Table 4 Correlation of bile acid pool with other} laboratory data

\begin{tabular}{lll}
\hline Laboratory data & Correlation coefficient & Statistical significance \\
\hline Serum $\beta$-carotene & $r=0.06$ & NS \\
Leucocyte count & $r=0.29$ & NS \\
Serum albumin & $r=0.23$ & NS \\
Serum cholesterol & $r=0.68$ & P $<0.01$ \\
ESR & $r=0.72$ & P $<0.01$ \\
\hline
\end{tabular}

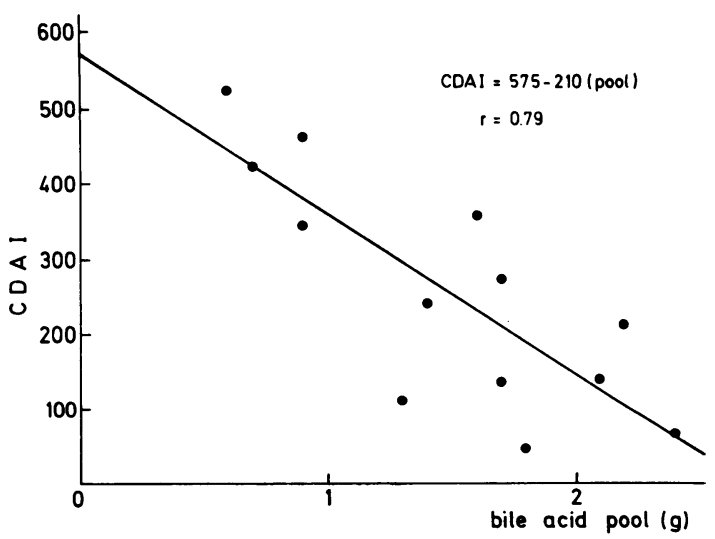

Fig. 3 Crohn's disease activity index (CDAI) and bile acid pool size. 
Group (Best et al., 1976). Talstad and Gjone (1976), using a different index, found that the erythrocyte sedimentation rate was fairly well correlated with the activity of Crohn's disease. In our studies both the erythrocyte sedimentation rate and the serum cholesterol level correlated with the activity of the disease (Table 4). However, the parameter which correlated best with the activity index was the bile acid pool size: the more active the disease, the lower the pool size (Fig. 3).

We acknowledge the technical assistance of Mrs S. Rutten and Mr L. Verhaegen. This research was sponsored by grants from the Fonds voor Wetenschappeliik Geneeskundig Onderzoek van België, Brussels, Belgium.

\section{References}

Austad, W. I., Lack, L., and Tyor, M. P. (1967). Importance of bile acids and of an intact distal small intestine for fat absorption. Gastroenterology, 52, 638-646.

Best, W. R., Becktel, J. M., Singleton, J. W., and Kern, F., Jr. (1976). Development of a Crohn's disease activity indexNational cooperative Crohn's disease study. Gastroentero$\log y, 70,439-444$.

Bremmelgaard, A., and Pedersen, L. (1976). Bile acids in bile during long-term chenodeoxycholic acid treatment. Scandinavian Journal of Gastroenterology, 11, 161-165.

Bruusgaard, A. (1970). Quantitative determination of the major 3-hydroxy bile acids in biological material after thinlayer chromatographic separation. Clinica Chimica Acta, 28, 495-504.

Bruusgaard, A., and Thaysen, E. (1970). Increased ratio of glycine/taurine conjugated bile acids in the early diagnosis of terminal ileopathy. Acta Medica Scandinavica, 188, 547548.

Dowling, R. H., Mack, E., and Small, D. (1970). Effects of controlled interruption of the enterohepatic circulation of bile salts by biliary diversion and by ileal resection on bile salt secretion, synthesis and pool size in the rhesus monkey. Journal of Clinical Investigation, 49, 232-242.

Dowling, R. H., Bell, G. D., and White, J. (1972). Lithogenic bile in patients with ileal dysfunction. Gut, 13, 415-420.

Duane, C., Adler, R., Bennion, L., and Ginsberg, R. (1975). Determination of bile acid pool size in man: a simplified method with advantages of increased precision, shortened analysis time, and decreased isotope exposure. Journal of Lipid Research, 16, 155-158.

Dyer, N., Stansfeld, A., and Dawson, A. (1970). The value of rectal biopsy in the diagnosis of Crohn's disease. Scandinavian Journal of Gastroenterology, 5, 491-496.

Eyssen, H. J., Parmentier, G., and Mertens, J. (1976). Sulfated bile acids in germ-free and conventional mice. European Journal of Biochemistry, 66, 507-514.

Garbutt, J., Heaton, K., Lack, L., and Tyor, M. (1969). Increased ratio of glycine- to taurine-conjugated bile salts in patients with ileal disorders. Gastroenterology, 56, 711-720.

Goodman M., Skinner, J., and Truelove, S. (1976). Abnormalities in the apparently normal bowel mucosa in Crohn's disease. Lancet, 1, 275-278.

Heaton, K., and Read, A. (1969). Gall stones in patients with disorders of the terminal ileum and disturbed bile salt metabolism. British Medical Journal, 3, 494-496.

Hofmann, A. F. (1967). The syndrome of ileal disease and the broken enterohepathic circulation: cholerheic enteropathy. Gastroenterology, 52, 752-757.

Hofmann, A. F. (1962). Thin-layer adsorption chromatography of free and conjugated bile acids in silicic acid. Journal of Lipid Research, 3, 127-128.

Hofmann, A. F., and Poley, J. R. (1969). Cholestyramine treatment of diarrhea associated with ileal resection: factors influencing response. (Abstract.) Gastroenterology, 56, 1168.

Hofmann, A. F., and Poley, J. R. (1972). Role of bile acid malabsorption in pathogenesis of diarrhea and steatorrhea in patients with ileal resection. Gastroenterology, 62, 918934.

Koss, F., Mayer, D., and Haindl, H. (1965). Methoden der enzymatischen Analyse, pp. 1824-1827. Edited by $\mathrm{H}$. Bergmeyer. Verlag Chemie: Weinheim.

Lenz, K. (1975). An evaluation of the breath test in Crohn's disease. Scandinarian Journal of Gastroenterology, 10, 665671.

Makino, I. Shinozaki, K., and Yoshino, K. (1975). Dissolution of cholesterol gallstones by long term administration of ursodeoxycholic acid. Japanese Journal of Gastroenterology, 72, 690-702.

Mallory, A., Kern, F., Smith, J., and Savage, D. (1973). Patterns of bile acids and microflora in the human small intestine. Gastroenterology, 64, 26-33.

Meihoff, W. E., and Kern, F. (1968). Bile salt malabsorption in regional ileitis, ileal resection and mannitol-induced diarrhea. Journal of Clinical Investigation, 47, 261-267.

Murphy, G. M., and Signer, E. (1974). Bile acid metabolism in infants and children. Gut, 15, 151-163.

Parmentier, G., and Eyssen, H. (1975). Synthesis of the specific monosulfates of cholic acid. Steroids, 26, 721-729.

Pomare, E., and Low-Beer, T. (1974). Measurement and validation of human bile salt pool size and synthesis. Clinica Chimica Acta, 57, 239-248.

Ruddell, W., Lovell, D., and Blendis, L. (1976). Bowel mucosa in Crohn's disease. Lancet, 1, 539-540.

Salen, M., Fedorowski, T., Colalillo, A., and Mosbach, E. H. (1976). Metabolism of ursodeoxycholic acid in man. (Abstract.) Gastroenterology, 70, 992.

Salen, G., Tint, G. S., Eliav, B., Deering, N., and Mosbach, E. H. (1974). Increased formation of ursodeoxycholic acid in patients treated with chenodeoxycholic acid. Journal of Clinical Investigation, 53, 612-621.

Schwarz, H. P., von Bergmann, K., and Paumgartner, G. (1974). A simple method for the estimation of bile acids in serum. Clinica Chimica Acta, 50, 197-206.

Stiehl, A., Raedsch, R., Regula, M., and Kommerell, B. (1975). Zur Behandlung von Patienten mit Cholesteringallensteinen mit Chenodesoxycholsäure: Veränderungen im Gallensäurenstoffwechsel. Innere Medizin, 2, 13-18.

Tabaqchali, S. (1970). The pathophysiological role of small intestinal bacterial flora. Scandinavian Journal of Gastroenterology, 5, suppl. 6, 139-163.

Talstad, I., and Gjone, E. (1976). The disease activity of ulcerative colitis and Crohn's disease. Scandinavian Journal of Gastroenterology, 11, 403-408.

van Deest, B., Fordtran, J., Morawski, S., and Wilson, J. (1968). Bile salt and micellar fat concentration in proximal small bowel contents of ileectomy patients. Journal of Clinical Investigation, 47, 1314-1324.

Vlahcevic, Z., Bell, C., Gregory, D., Buker, G., Juttijudata, P., and Swell, L. (1972). Relationship of bile acid pool size to the formation of lithogenic bile in female Indians of the Southwest. Gastroenterology, 62, 73-83. 